\title{
Pathological view of sudden cardiac death
}

\author{
MICHAEL J DAVIES
}

From the Department of Cardiovascular Pathology, St George's Hospital Medical School, London

SUMMARY The common cause of sudden cardiac death is ischaemic heart disease. Such patients may have an occlusive recent thrombosis in a major coronary artery but the largest group has no recent occlusion. Comparison of such patients without occlusion with non-cardiac death control hearts suggests that an area of stenosis of 85 per cent is the best discriminating level. Most subjects who die of ischaemic heart disease suddenly have this degree of stenosis in two or three major arteries. Non-ischaemic sudden cardiac death occurs in hypertrophic obstructive cardiomyopathy and in severe left ventricular hypertrophy particularly from aortic valve stenosis. When the heart is macroscopically normal, review of previous electrocardiograms is the most helpful guide and may disclose conditions such as a long QT interval or pre-excitation. When no such data are available examination of the conduction system histologically may be helpful but is often non-specific. Use of the term "cardiomyopathy" by pathologists to cover all non-ischaemic sudden cardiac death is clinically misleading.

The pathologist, when faced with investigating sudden cardiac death in an adult or a child over 1 year of age, can usually place the heart into one of three categories. In order of frequency these are ischaemic heart disease, conditions recognised macroscopically known to be associated with sudden death and, finally, hearts which are, at least to the naked eye, normal. There is an understandable temptation for the pathologist to transfer hearts in the third category to the first in adults since few coroners view "no clear cause of death" with enthusiasm. In children this way out is impossible and more exacting studies are more readily undertaken.

\section{Ischaemic heart disease}

Annually in the United Kingdom many thousands of patients dying suddenly from ischaemic heart disease come to a necropsy ordered by the coroner. It must be stressed that these forensic necropsies are to exclude unnatural death and not to provide accurate scientific data. In consequence, there is surprisingly little detailed knowledge of the pathology of ischaemic heart disease related to sudden death.

A proportion of these patients do have a recent occlusive thrombus in a major coronary artery. Death can be assumed to be from subsequent ventricular fibrillation. The proportion of cases with such a thrombus is reported to be from 4 to
64 per cent (Table 1). Such widely divergent figures are unlikely to be a true reflection of the pathology. The wide range reflects, in part, the degree of care taken or the beliefs of the individual pathologist. Even within a single pathological department the proportion of thrombi found by different individual consultant pathologists varies widely. ${ }^{16}$ Other factors which militate against comparability of series are different temporal definitions of the term "sudden", varying proportions of smokers to non-

Table 1 Frequency of recent occlusive coronary thrombosis in sudden death caused by ischaemic heart disease

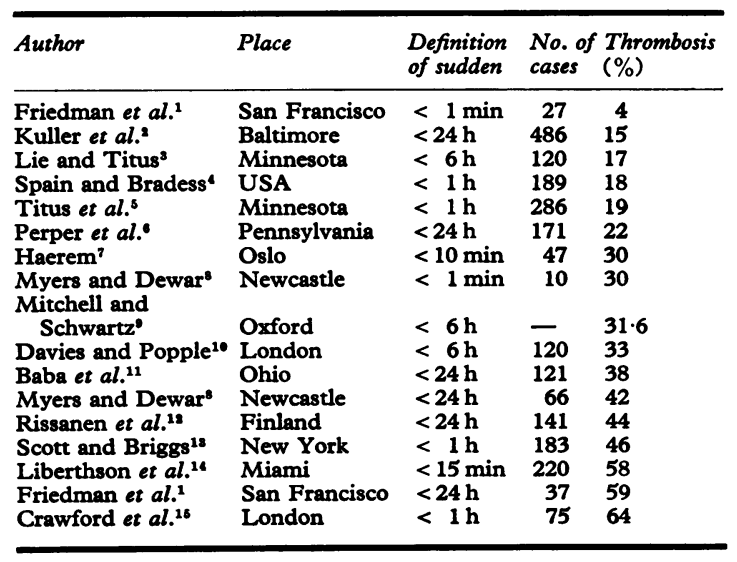


smokers, those with and without hypertension, and different age and sex ranges. Even when the available published data are grouped, however, by a definition of deaths within a minute (instantaneous), within six hours, or within 24 hours no consistent figures emerge for the incidence of occlusive thrombi. Our own continuing study ${ }^{10}$ of 120 sudden deaths within six hours from ischaemic heart disease suggests the incidence to be exactly 33 per cent (Table 1).

It is hardly surprising that sudden ventricular fibrillation should follow a coronary artery occlusion. The situation can be mimicked experimentally by coronary ligation in the dog. It is observed in patients with acute myocardial infarction who reach hospital. There is some evidence suggesting that right coronary artery occlusions are more often associated with sudden death. The limited published data available suggest that the ratio of right to left anterior descending artery occlusions is lower in patients dying in hospital of infarction than sudden death patients not reaching hospital (Table 2). James 1920 has reviewed the possible causes of this association which leads the right coronary to be regarded as the artery of sudden death. The major factor is the role of the right coronary artery in supplying both sinuatrial and atrioventricular nodes.

Table 2 Site of occlusive coronary thrombus in acute myocardial infarction and sudden ischaemic death

\begin{tabular}{|c|c|c|c|c|}
\hline No. & $\begin{array}{l}\text { Main } \\
\text { left }\end{array}$ & $L A D$ & $\boldsymbol{R}$ & $L C$ \\
\hline \multirow[t]{2}{*}{$\begin{array}{l}\text { Acute myocardial } \\
\text { infarction } \\
\text { (hospital deaths) } \\
\text { Plotz } \\
\text { Davies et al. } .^{16}\end{array}$} & $\begin{array}{l}71 \\
15\end{array}$ & $\begin{array}{l}834 \\
219\end{array}$ & $\begin{array}{l}379 \\
160\end{array}$ & $\begin{array}{r}211 \\
63\end{array}$ \\
\hline & 86 & $1053(54 \%)$ & $539(28 \%)$ & $274(14 \%)$ \\
\hline \multirow[t]{2}{*}{$\begin{array}{lr}\text { Sudden death } & \\
\text { Friedman et al. } & 21 \\
\text { Davies and } & \\
\text { Popple } & \\
\text { Myers and Dewar } & 39 \\
\text { Crawford et al. } & 40 \\
\text { Bashe et al. } & 48 \\
\text { Ba } & 46\end{array}$} & $\begin{array}{l}1 \\
0 \\
0 \\
0 \\
3\end{array}$ & $\begin{array}{l}11 \\
18 \\
12 \\
27 \\
16\end{array}$ & $\begin{array}{l}7(33 \%) \\
16(41 \%) \\
19(48 \%) \\
15(31 \%) \\
19(41 \%)\end{array}$ & $\begin{array}{l}2 \\
9 \\
9 \\
9 \\
6 \\
8\end{array}$ \\
\hline & 4 & $84(43 \%)$ & $76(39 \%)$ & $34(18 \%)$ \\
\hline
\end{tabular}

All pathological studies agree in that there is a second large group of patients who do not have an occlusive thrombus or, indeed, any easily demonstrable recent morphological change in the coronary arteries. This second group of patients has coronary stenosis caused by atherosclerosis but for the pathologist the difficulty is in defining the minimal degree of disease which is sufficient to be causally

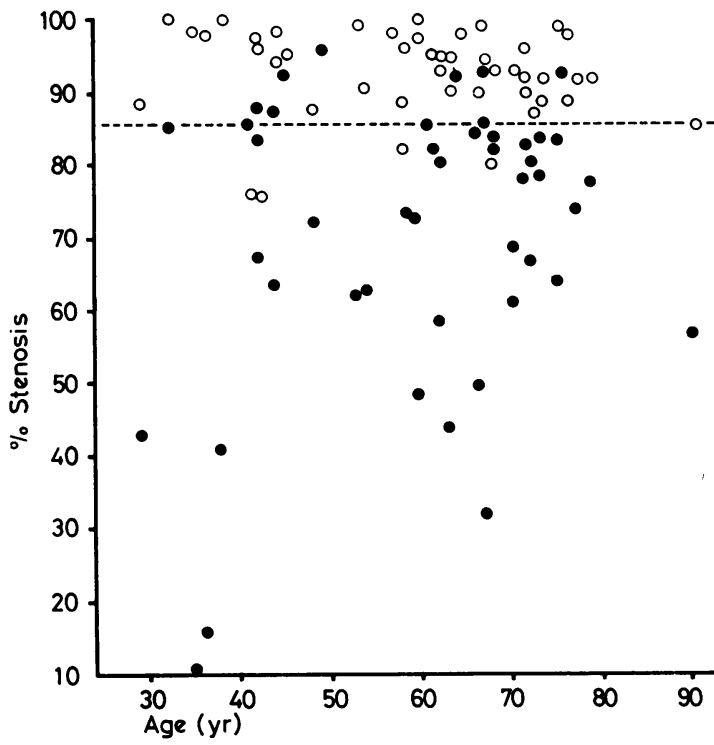

Fig. Comparison of the single worst area of coronary artery stenosis and age in male patients dying suddenly $(<6 h)$ of ischaemic heart disease (open circles) and age matched non-cardiac deaths (closed circles).

The majority of ischaemic deaths show stenosis at least at one point of over 85 per cent. Some control hearts, however, show an identical degree of stenosis.

related to death. Our own studies quantifying in detail the degrees of coronary stenosis suggest that for practical purposes 85 per cent stenosis at any single point is the lower limit (Fig.). Statistically, the best breakpoint between control and test groups is $\mathbf{7 5}$ per cent stenosis. The majority of the patients in the test group with over 75 per cent stenosis have double or triple vessel disease (Table 3 ), but a minority of 12 per cent has this degree of stenosis in only one major vessel. The problem with such figures, for the pathologist, is in that a group of age and sex matched control hearts from patients dying with intracerebral tumours or from trauma overlap the test group in the degree of coronary artery disease (Fig.). In such a control group 12 per cent

Table 3 Frequency of arteries with more than 75 per cent stenosis in any one $0.4 \mathrm{~cm}$ segment : age-sex matched controls

\begin{tabular}{lcc}
\hline No. of arteries & $\begin{array}{l}\text { Test } \\
(\%)\end{array}$ & $\begin{array}{l}\text { Controls } \\
(\%)\end{array}$ \\
\hline 0 & $11^{\star}$ & 52 \\
1 & 12 & 21 \\
2 & 18 & 19 \\
3 & 49 & 8 \\
\hline
\end{tabular}

$\star$ ? One death wrongly certified at necropsy. 
of subjects had stenosis of over 85 per cent at some point in the coronary tree (Fig. 1). This overlap represents the high background level of atherosclerosis in our population. Comparing single, double, and triple vessel disease in the control and test groups, longer segments of diseased vessel are found in the latter but again there is overlap of the groups. The number of patients in the general population with over 85 per cent stenosis at some point is too high to be explicable by competing causes of death, that is if the patient had not developed a cerebral tumour he would have died the next year from ischaemic heart disease.

Clinical studies of resuscitated "sudden death" patients ${ }^{142122}$ support the concept that there are two groups of patients, one which develops myocardial infarction and one which does not. The mechanism of death in this latter group once again seems to be the onset of ventricular fibrillation. ${ }^{21-26}$ The myocardial resistance to ventricular fibrillation, that is its "electrical stability", may be one factor separating test and control patients with identical degrees of coronary disease but one dying the other living. ${ }^{27}$ Epidemiological evidence suggests that the different mortality rates from ischaemic heart disease in hard and soft water areas ${ }^{28-30}$ are not the result of differences in the degree of stenosis and are, therefore, presumably mediated by the differences in electrical stability of the myocardium. This may reflect altered ion concentrations in the myocardium, particularly of calcium and magnesium. ${ }^{31}$ In patients whose electrical stability is lowered by coronary artery stenosis the precipitating factor to invoke ventricular fibrillation may be sympathetic stimulation or neural or psychological factors. ${ }^{27}$

To demonstrate a morphological cause for myocardial instability is the wish of many pathologists. The reported proportion of patients with ischaemic heart disease dying suddenly who have a degree of myocardial necrosis (that is anything from a tiny focus of $0.1 \mathrm{~mm}$ to a large regional infarct) is very wide, from 12 to 85 per cent. ${ }^{3}{ }^{32}$ The lower figures are from those who use naked eye examination only, the higher when refined "histochemical" stains are used. The difficulty with the latter technique is the occurrence of very high positive results in control patients, a failure to distinguish true from agonal myocardial changes.

The problem is also one of the timing of death. A proportion of those cases with an occlusive thrombus can be predicted to develop regional myocardial infarction but when death occurs within 12 hours it is difficult for the pathologist to demonstrate necrosis. Figures from Seattle ${ }^{26}$ indicate that only 19 per cent of patients resuscitated from "sudden death" do develop myocardial infarction demonstrable by the electrocardiogram. Since it is well known to pathologists ${ }^{9} 33$ that not all occlusive thrombi produce myocardial infarction the Seattle figures probably underestimate the incidence of occlusive thrombi. The occlusion when present does, however, act as a trigger to provoke ventricular fibrillation.

Platelet emboli into small intramyocardial arteries from more proximal, but non-occlusive, complex atheromatous plaques or thrombi are postulated to cause sudden death. ${ }^{74}$ Since there is extreme difficulty in demonstrating disintegrated platelets by conventional histological techniques it is impossible to confirm or refute the suggestion absolutely. It is certainly possible that a shower of disintegrating platelets may not only block small arteries but their "pharmacological" contents could provoke intense spasm more distally. Most pathologists have seen isolated cases where platelet emboli are found, but my experience suggests it to be rare, at least in any form demonstrable by conventional methods. The role of pure coronary artery spasm is clearly not amenable to investigation in the dead heart and must remain speculative. ${ }^{35}$ It is apparent that a great deal more work on sudden ischaemic death is needed. It is salutary to consider that despite many thousands of necropsies a year in the United Kingdom we still do not know if the incidence of thrombi differs in smokers and non-smokers and whether the high rate of sudden death in Scotland as compared with the rest of the United Kingdom ${ }^{36}$ is associated with differences in the coronary artery pathology.

\section{Cardiac death not caused by coronary atheroma}

The second major group of hearts are those with recognisable, if unrecognised, non-ischaemic cardiac disease. Any cause of severe left ventricular hypertrophy but particularly aortic valve stenosis may be associated with sudden death. In practice, hearts of a total weight over $550 \mathrm{~g}$ will have sufficient ventricular hypertrophy to be reasonably associated with sudden death. In cases of aortic stenosis subendocardial recent necrosis is usually demonstrable in the left ventricle. Gross right ventricular hypertrophy also carries a risk of sudden death usually associated with previously unrecognised pulmonary valve stenosis, obstructive cardiomyopathy, or primary pulmonary hypertension. All the examples seen personally have had isolated right ventricular weights of over $110 \mathrm{~g}$.

Hypertrophic obstructive cardiomyopathy (HOCM) continues to be missed by pathologists at 
Table 4 Sudden death

\begin{tabular}{lccc}
\hline & $\begin{array}{l}\text { Undiagnosed } \\
\text { HOCM }\end{array}$ & $\begin{array}{l}\text { HOCM } \\
\text { diagnosed/ } \\
\text { symptomatic }\end{array}$ & $\begin{array}{l}\text { HOCM } \\
\text { coincidental } \\
\text { finding }\end{array}$ \\
\hline Male & $41(85 \%)$ & $10(62.5 \%)$ & $6(50 \%)$ \\
Female & $\frac{7}{48}$ & -16 & $\frac{6}{12}$ \\
Heart weight & $478 \pm 136$ & $526 \pm 123$ & $\frac{12}{470 \pm 95}$ \\
S/P ratio & $1.8(1.4-2 \cdot 6)$ & $1.9(1.6-2.3)$ & $2 \cdot 2(1 \cdot 7-2.3)$ \\
\hline
\end{tabular}

necropsy largely because of a failure to appreciate its wide morphological spectrum and by opening the left ventricular outflow tract through the anterior cusp of the mitral valve. This technique successfully masks the encroachment of the septum dn the ventricular outflow tract. In my experience sudden death is seen particularly in men (Table 4) and has been reported to occur particularly in certain families. ${ }^{37}{ }^{38} \mathrm{I}$ have found no morphological features to distinguish those cases dying suddenly from those not. I have seen examples from under 10 to over 80 years of age at the time of sudden death. The pathologist should suspect hypertrophic cardiomyopathy in any heart showing ventricular hypertrophy with a small left ventricular cavity for which there is no obvious cause. Far too many cases of HOCM are labelled as hypertensive cardiomegaly by pathologists. Inclusion as a standard necropsy practice of measurement of the septum and posterior wall with ratios over 1.6 confirms many of these cases to be hypertrophic cardiomyopathy. I have not observed aortic valve stenosis to produce this figure (Table 5). In

Table 5 Septal/posterior wall ratios-necropsy hearts

$\begin{array}{lll}\text { Non-cardiac deaths normal weight hearts } & (n=108) & 1.02 \pm 0.24 \\ \text { Cardiac deaths LV hypertrophy } & (n=37) & 1.10 \pm 0.24 \\ \text { HOCM } & (n=73) & 1.9 \pm 0.86\end{array}$

Only $4 / 3$ HOCM hearts had ratio $<1.5$

hypertrophic cardiomyopathy gross hypertrophy of the free left ventricular wall, on occasions, tends to mask the septal asymmetric hypertrophy leading to an erroneous diagnosis of "hypertensive" cardiomegaly. It is not widely appreciated that asymmetric hypertrophy, in fact, may be symmetric at necropsy. ${ }^{39}$ When echocardiograms of such patients are available the asymmetry is often seen to be more apparent in diastole, and it is in the contracted postmortem heart that problems in diagnosis arise. On rare occasions the mass of abnormal muscle is not septal. A reversal of the septal/posterior wall ratio may also therefore indicate hypertophic cardiomyopathy provided that no old septal infarction is present. ${ }^{40}$ Subaortic endocardial thickening resulting from contact between the anterior cusp of the mitral valve and the septum is always a valuable confirmatory feature in cases of HOCM with outflow obstruction. Cardiomyopathy of the congestive form is not, in my experience associated to any obvious degree with sudden death without a prior long period of left ventricular failure.

Deposition of amyloid can cause sudden death particularly when advanced in degree and involving the conduction system. Care must be taken by the pathologist not to overinterpret the finding of amyloid in the heart. A high proportion of elderly patients at necropsy have nodules of a substance staining as myloid in the left atrium. This appears to have little functional effect other than a tendency to be associated with atrial fibrillation. ${ }^{41}$

Acute myocarditis of all forms is associated with sudden death; commonly there is a history of some days' malaise, fever, and tachycardia or palpitation. More rarely the patient drops dead as the presenting feature. It is usually possible to suspect the diagnosis macroscopically; the myocardium is mottled, the left ventricle dilated but with no cardiomegaly. Pericarditis is usually present in viral myocarditis. Idiopathic giant cell myocarditis has serpiginous areas of myocardial necrosis easily seen with the naked eye. Myocardial sarcoidosis is associated with obvious scarring, particularly in the septum, and is easily confirmed histologically.

Once again caution must be used to avoid overdiagnosis of myocarditis at necropsy. Isolated foci of lymphocytes in the atrial myocardium, while strictly termed myocarditis on morphological grounds, are common in all elderly hearts and may be erroneously related to death by pathologists wishing to find a cardiac abnormality. In cases of death actually caused by myocarditis virtually every histological block from the ventricular muscle, and often from the conduction system itself, is involved.

Sudden death may occur in patients with floppy mitral valves, yet without severe mitral regurgitation. The frequency of the valve abnormality in the population is of the order of 5 per cent ${ }^{42}$ so the risk of death to any individual patient with a floppy mitral valve must be very small. It is my experience as a pathologist that occasional patients with a mild to moderate floppy valve are indeed found without other ascertainable cause of death. On the very few occasions that we have been able to obtain a previous electrocardiogram it has been abnormal with inversion of $T$ waves in the inferolateral leads. It seems likely that, as shown previously, ${ }^{43}$ this pattern defines a subset of patients with floppy 
valves who have a tendency to sudden death. Patients with a mild floppy valve and a normal electrocardiogram probably have no such risk.

The mechanism underlying these electrocardiographic abnormalities is debatable. ${ }^{44-46}$ It has been ascribed to be associated with a primary muscle abnormality, mechanical traction on papillary muscles, endocardial impact with the valve, anomalous coronary arteries, and interference with left circumflex flow. In my experience I have been unable to demonstrate any morphological abnormality in the left ventricle. If this is a subtle abnormality of myocardial repolarisation it is uncertain if the association with a floppy mitral valve is fortuitous or linked by a close chromosomal position of two genes.

Anomalous coronary artery anatomy ${ }^{47}$ may be perfectly benign or produce serious functional effects. Where the abnormality is a simple one of both coronary orifices arising from the same sinus or a single orifice there is no risk of sudden death. The commonest form is to find a single or two orifices in the right coronary sinus. The left anterior descending coronary artery crosses in front of the right ventricular outflow. A personal study of 2240 hearts disclosed five such cases, all asymptomatic and dying of non-cardiac disease.

Sudden death is a risk either when a segment of the coronary artery tree is aplastic or when there is a coronary shunt. Most frequently the former is a single right coronary orifice with the left anterior descending artery passing behind the pulmonary artery and being represented as a fibrous strand without a lumen. Coronary shunts occur with a fistula from an artery into the ventricles, atria, or coronary sinus. Aneurysmal dilatation of the coronary artery involved ensues and myocardial perfusion becomes abnormal. Anomalous origin of one coronary artery from the pulmonary artery also leads to an aortic-pulmonary shunt.

Coronary embolism is a cause of sudden death. Emboli occur most frequently from aortic valve thrombus as in bacterial endocarditis. The aortic Starr-type prosthetic valve with its peripheral flow into the sinuses seems almost to direct emboli into the coronary orifices. Syphilitic ostial stenosis as a postulated cause of sudden death ${ }^{48}$ has virtually vanished.

Small myxomatous polyps on the aortic valve may prolapse into a coronary orifice orifice but are extremely rare. ${ }^{49}$ Isolated dissection of coronary arteries occurs occasionally to produce sudden death in Marfan's syndrome and also in pregnancy..$^{50}{ }^{51}$ Coronary arteritis occurs in polyarteritis nodosa ${ }^{52}$ and sudden death is well described. ${ }^{19}$ In Japan a striking syndrome of lymphadenopathy, skin rash, conjunctivitis, and fever in young children with a high risk of sudden death from coronary arteritis is relatively common but sporadic cases are now known to occur both in the United Kingdom and the United States. ${ }^{53}$

When all other known causes of sudden death have been excluded macroscopical examination of the area of the conduction system is, on occasion, helpful. The small benign mesothelial tumour of the atrioventricular node ${ }^{5455}$ is usually visible as a 1 to $2 \mathrm{~cm}$ cystic mass in the atrial septum anterior to the coronary sinus. Calcific masses originating from the anterior cusp of the mitral or the aortic valve may also transect the area of the main bifurcating atrioventricular bundle.

It is when the pathologist is faced with a heart apparently totally normal to external examination that practical problems arise.

The majority of pathologists have a very liberal interpretation of the term cardiomyopathy and, to the clinicians' confusion, apply it indiscriminately for such cases. Fully developed congestive cardiomyopathy (COCM) does have recognisable morphological abnormalities. At macroscopical level these include raised ventricular muscle weights for both ventricles, dilatation of the ventricular cavities leading to a normal or even reduced wall thickness, mural thrombus in all chambers, and diffuse endocardial thickening in the left ventricle. Microscopical examination of the myocardium shows interstitial fibrosis, reduced muscle fibre diameters with a wide scatter in size, and vacuolated fibres with hyperchromatic large nuclei. It would clarify semantics if pathologists would confine the term congestive cardiomyopathy to patients known to have a degree of left ventricular failure and whose heart showed at least three of the morphological abnormalities listed. As stated above, my own experience is that such hearts are rarely causes of instantaneous sudden death.

A number of conditions deserving better recognition is also squeezed into a "cardiomyopathy" group by pathologists. Isolated increase in the heart weight is better termed idiopathic cardiomegaly. Most examples are probably an excessive hypertrophy response to unrecorded hypertension and are particularly seen in patients of West Indian origin.

Widespread interstitial or focal myocardial fibrosis without other morphological abnormality is best termed idiopathic myocardial scarring and may well be post-viral myocarditis. This group of patients, clinically, may be associated with arrhythmic problems entirely without evidence of abnormal myocardial contractile function.

Macroscopically, normal hearts are also en- 
countered in which a selective and progressive loss of conduction fibres occurs followed by replacement fibrosis. These hearts are again not associated with evidence of loss of contractile junction but develop arrhythmias and conduction defects. No name is available for this entity but "conduction myopathy" might be appropriate.

Those hearts which comprise the group where there is no macroscopical abnormality and no microscopical abnormality of the contractile myocardium do pose a major problem for the pathologist. In practice, many of these patients are simply transferred to the ischaemic or cardiomyopathy groups since a great deal of further effort and public cost are thus avoided. Hearts from patients under the age of 50, and particularly under 30 , are those more extensively studied.

The initial step is to exclude once again unnatural death, in particular a concealed suicide. Blood should be screened for drugs by gas chromatography. After these steps have been carried out death can be presumed to be cardiac in origin. A detailed medical history from the family is sought and any electrocardiogram ever taken reviewed. The conduction system is examined histologically.

Personal experience of studying such patients, suggests that the majority of deaths are indeed cardiac. My experience is of necessity selected by pathologists who know of my interest. In 57 hearts referred for investigation of sudden death without macroscopical abnormality and a normal myocardium, 25 proved to have had previous electrocardiograms, all recorded in the investigation of palpitation or syncopal attacks of varying severity and frequency. The electrocardiographic abnormalities are shown in Table 6 . Several of these, such as pre-excitation, have a well-defined risk of sudden death and with careful morphological study anomalous pathways, often multiple, can be found..$^{56}$ The long QT interval syndrome has a similar well-recognised clinical association with sudden

Table 6 Twenty-five patients without macroscopical abnormality of heart

\begin{tabular}{|c|c|c|}
\hline $\begin{array}{l}\text { Previous electrocardiographic } \\
\text { data obtained } \\
\text { Electrocardiographic } \\
\text { abnormality }\end{array}$ & No. & $\begin{array}{l}\text { All }<50 \text { years of age } \\
\text { Conduction system } \\
\text { morphology }\end{array}$ \\
\hline $\begin{array}{l}\text { Pre-excitation } \\
\text { Long QT interval } \\
\text { Episodic supraventricular } \\
\text { tachycardia } \\
\text { Multifocal ventricular/atrial } \\
\text { ectopics } \\
\text { Some ventricular ectopic beats } \\
\text { AV block (partial) } \\
\text { Bundle-branch block } \\
\text { (partial or complete) }\end{array}$ & $\begin{array}{l}3 \\
7 \\
1 \\
4\end{array}$ & $\begin{array}{l}\text { Anomalous pathways } \\
\text { Normal } \\
\text { Normal } \\
\text { Normal } \\
\text { Normal } \\
\text { Mesothelioma AV node } \\
\text { Fibrosis and hypoplasia } \\
\text { of bundle-branches }\end{array}$ \\
\hline
\end{tabular}

death $^{57} 58$ but a histologically normal conduction system. James et al. ${ }^{59}$ however, record nerve fibre pathology in this group.

Patients with ectopic beats and supraventricular tachycardias universally proved to have a morphologically normal conduction system, and, clearly, the pathophysiological abnormality is beyond conventional histology. This group must, however, be pathologically distinguished from those patients with widespread myocardial scarring who have a similar clinical picture and can be postulated to represent a post-viral myocarditis aetiology.

Patients in whom the electrocardiogram showed conduction defects can be shown to have morphological abnormality. Destruction of the atrioventricular node is characteristic of the small mesothelioma which may be no more than $0.3 \mathrm{~cm}$ across and escape macroscopical examination.

The Lenegre and Lev forms of idiopathic bundlebranch fibrosis which characteristically lead to complete atrioventricular block in patients over $\mathbf{5 0}$ and often over 65 years of age are associated with steadily progressive electrocardiographic changes over many years. ${ }^{60-62}$ At the stage where right bundle-branch block and left axis deviation is present indicating bilateral bundle-branch damage sudden death occurs but the exact risk and detection of those at risk is debated. ${ }^{63} 64$

Congenital or familial conduction defects at bundle-branch level may be relatively stable and not progress. These appear to represent aplasia or extreme hypoplasia of one segment, usually the proximal right branch. The essential pathology is therefore akin to congenital atrioventricular block. ${ }^{65}$ Such conditions appear to have a relatively low risk of sudden death. ${ }^{68}$ In contr..3t, patients and families in whom the electrocardiographic abnormality is progressive are at risk of sudden death. ${ }^{67-70}$ Published reports and the four cases in Table 6 all show widespread loss of conduction fibres throughout the distal conduction system. It is to this group that the term "conduction myopathy" might be applied. It remains uncertain whether this abnormality in patients under 50 years of age is identical to the Lenegre form of bundle-branch fibrosis which produces complete atrioventricular block in older patients. It is probable that they are simply different ends of a clinical and age spectrum.

Consideration of the clinical history of those patients without a previous electrocardiogram suggests (Table 7) that many of these would have been abnormal. Retrospective questioning of relatives of 25 of $37(68 \%)$ disclosed suspicious symptoms. In retrospect, one case was likely to be the clinical syndrome of undue catecholamine sensitivity. ${ }^{71}$ 
Table 7 Thirty-seven patients dying suddenly-no electrocardiographic data available. No macroscopical cause apparent-myocardium normal (ages 5 to 49)

\begin{tabular}{lr} 
Clinical data & 14 \\
Palpitation alone & 4 \\
Palpitation and syncopal or fainting attacks & 3 \\
Syncopal attacks alone & 3 \\
Family history of sudden death & 12 \\
No complaints known & 1 \\
Sibs with long QT & 37 \\
\hline & \\
\hline Conduction system morphology & 2 \\
Mesothelioma AV node & 10 \\
Anomalous conduction path (Mahaim type) & 2 \\
Absent right bundle-branch & 2 \\
Hypoplasia main atrioventricular bundle or bundle-branches & 5 \\
Fibrosis bundle-branches and distal conduction fibres & 16 \\
Normal & 37 \\
\hline
\end{tabular}

As a basic principle, examination of the conduction system where no electrocardiographic data are available is seldom scientifically profitable. The incidence of morphological abnormality in this group is, however, high, and closely mirros s that found in the patients with electrocardiographic data.

Mesotheliomata when present are clearly the cause of death. Where distal conduction fibre loss has occurred this again is likely to be significant. Mahaim tracts are of dubious significance since they are relatively common in children who die accidentally. Where the conduction system is morphologically normal no conclusions can even be attempted. It must be admitted that cases will occur where no firm cause of death can be ever ascertained.

There is strong pressure on the pathologist undertaking these studies to find a lesion and numerous individual cases of sudden death associated with minor morphological abnormalities become recorded. ${ }^{197273}$ Before these can be scientifically established as cause and effect many more morphological studies must be made of patients in whom electrocardiographic and particularly 24-hour monitoring has been recorded. The forensic necropsy service in England and Wales, even so, is not set up to recover such hearts and, while its sole responsibility is to exclude unnatural death, will not do so.

I am grateful to numerous pathologists who send me material, without whom this work would be impossible. Dr A Leatham and Dr D Krikler have interpreted many of the electrocardiograms with great patience. Detailed coronary assessment was carried out by Dr A Popple as part of an MD thesis.

\section{References}

'Friedman M, Manwaring JH, Rosenman RH, Donlon G, Ortego P, Grube SM. Instantaneous and sudden deaths: clinical and pathological differentiation in coronary artery disease. $\mathcal{F} A M A$ 1973; 225 : 1319-28.

${ }^{2}$ Kuller LH, Cooper M, Perper J, Fisher R. Myocardial infarction and sudden death in an urban community. Bull NY Acad Med 1973; 49: 532-43.

${ }^{3}$ Lie JT, Titus JL. Pathology of the myocardium and the conduction system in sudden coronary death. Circulation 1975; 51 and 52, suppl 3: 41-52.

${ }^{4}$ Spain DM, Bradess VA. Sudden death from coronary heart diseáse. Survival time, frequency of thrombi and cigarette smoking. Chest 1970; 58: 107-10.

${ }^{5}$ Titus JL, Oxinan HA, Connolly DC, and Nobrega FT. Sudden unexpected death as the initial manifestation of coronary heart disease. Clinical and pathological observations. Sinfapore Med f 1973; 14: 291-3.

'Perper JA, Kuller LH, Cooper M. Arteriosclerosis of coronary arteries in sudden unexpected deaths. Circulation 1975; 51 and 52, suppl 3: 27-33.

${ }^{7}$ Haerem JW. Mural platelet microthrombi and major acute lesions of main epicardial arteries in sudden death. Atherosclerosis 1974; 19: 529-41.

${ }^{8}$ Myers A, Dewar HA. Circumstances attending 100 sudden deaths from coronary artery disease with coroner's necropsies. Br Heart f 1975; 37 : 1133-43.

${ }^{9}$ Mitchell JRA, Schwartz CJ. Arterial disease. Oxford: Blackwell, 1965.

${ }^{10}$ Davies MJ, Popple AW. Sudden unexpected cardiac death-a practical approach to the forensic problem. Histopathology 1979; 3: 255-77.

${ }^{11}$ Baba N, Bashe WJ Jr, Keller MD, Geer JC, Anthony JR. Pathology of atherosclerotic heart disease in sudden death. I. Organising thrombus and acute coronary vessel lesions. Circulation 1975; 51 and 52, suppl 3: 53-9.

${ }^{12}$ Rissanen V, Romo M, Siltanen P. Prehospital sudden death from ischaemic heart disease-a postmortem study. Br Heart f 1978; 40: 1025-33.

${ }^{13}$ Scott RG, Briggs RS. Pathological findings in prehospital deaths due to coronary atherosclerosis. $\mathrm{Am} \mathcal{F}$ Cardiol 1972; 29: 782-7.

${ }^{14}$ Liberthson RR, Nagel EL, Hirschman JC, Nussenfeld SR, Blackborne BD, Davies JH. Pathophysiologic observations in pre-hospital ventricular fibrillation and sudden cardiac death. Circulation 1974; 49: 790-8.

${ }^{15}$ Crawford T, Dexter D, Teare RD. Coronary artery pathology in sudden death from myocardial ischaemia. Lancet 1961; 1 : 181-5.

${ }^{16}$ Davies MJ, Woolf N, Robertson WB. Pathology of acute myocardial infarction with particular reference to occlusive coronary thrombi. Br Heart $\mathcal{F}$ 1976; 38: 659-64.

${ }^{17}$ Plotz M. Coronary heart disease. London: Cassell, 1957. ${ }^{18}$ Bashe WJ Jr, Baba N, Keller MD, Geer JC, Anthony JR. Pathology of atherosclerotic heart disease in sudden death. II. The significance of myocardial infarction. Circulation 1975; 52, suppl 3: 63-77.

${ }^{19}$ James TN. De subitaneis mortibus. XXVII. Apoplexy of the heart. Circulation 1978; 57: 385-91. 
${ }^{20} \mathrm{James}$ TN. Pathogenesis of arrhythmias in acute myocardial infarction. Am $\mathcal{f}$ Cardiol 1969; 24: 791-9.

${ }^{21}$ Baum RS, Alvarez H III, Cobb LA. Survival after resuscitation from out of hospital ventricular fibrillation. Circulation 1974; 50: 1231-5.

${ }^{22}$ Scahffer WA, Cobb LA. Recurrent ventricular fibrillation and modes of death in survivors of out-ofhospital ventricular fibrillation. $N \mathrm{Engl} f \mathrm{Med} 1975$; 293: 259-62.

${ }^{23}$ Bleifer SB, Bleifer DJ, Hansmann DR, Sheppard JJ, Karpman HL. Diagnosis of occult arrhythmias by Holter electrocardiography. Prog Cardiovasc Dis 1974; 16: 569-99.

${ }^{24}$ Pool J, Kunst K, Van Wermeskerken JL. Two monitored cases of sudden death outside hospital. Br Heart $\mathcal{F}$ 1978; 40: 627-9.

${ }^{25}$ Gradman AH, Bell PA, DeBusk RF. Sudden death during ambulatory monitoring; clinical and electrocardiographic correlations. Report of a case. Circulation 1977; 55: 210-1.

${ }^{26}$ Cobb LA, Hallstrom AP, Weaver DW, Copass MK, Haynes RE. Clinical predictors and characteristics of the sudden cardiac death syndrome. Proceedings first US/USSR symposium on sudden death. Yalta, 1977. US Public Health Service. NIH Publ No. 78-1470, 1978, 99-116.

${ }^{27}$ Lown B. Sudden cardiac death: the major challenge confronting contemporary cardiology. Am $\mathcal{f}$ Cardiol $1979 ; 43$ : 313-28.

${ }^{28}$ Crawford MD, Clayton DG, Stanley F, Shaper AG. An epidemiological study of sudden death in hard and soft water areas. $\mathcal{F}$ Chronic Dis 1977 ; 30: 69-80.

${ }^{29} \mathrm{Crawford} T$, Crawford MD. Prevalence and pathological changes of ischaemic disease in a hard and in a soft water area. Lancet 1967; 1: 229-32.

${ }^{30}$ Anderson TW, LeRiche WH, Mackay JS. Sudden death in ischaemic heart disease; correlation with hardness of local water supply. $N$ Engl f Med 1969; 280: 805-7.

${ }^{31}$ Chipperfield B, Chipperfield JR. Relation of myocardial metal concentration to water hardness and death rates from ischaemic heart disease. Lancet 1979; 2: 709-12.

${ }^{32}$ Reichenbach DD, Moss NS. Myocardial necrosis and sudden deaths in humans. Circulation 1975; 51 and 52, suppl 3: 60-2.

${ }^{33}$ Fulton WFM. The coronary artery-arteriography, microanatomy and pathogenesis of obliterative coronary artery disease. Springfield, Illinois: Charles C Thomas, 1965.

${ }^{34}$ Frink RJ, Trowbridge JO, Rooney PA Jr. Nonobstructive coronary thrombosis in sudden cardiac death. Am f Cardiol 1978; 42: 48-51.

${ }^{35}$ Hellstrom RA. Evidence in favour of the vasospastic cause of coronary artery thrombosis. Am Heart $\mathcal{F} 1979$; 97: 449-52.

${ }^{36}$ Lancet. Editorial. Scottish hearts. 1979; 2: 726-7.

${ }^{37}$ Maron BJ, Roberts WC, Edwards JE, McAllister HA Jr, Foley DD, Epstein SE. Sudden death in patients with hypertrophic cardiomyopathy: characterization of 26 patients without functional limitation. $A m \mathcal{F}$ Cirdiol 1978; 41 : 803-10.

${ }^{38}$ Maron BJ, Lipson LC, Roberts EC, Savage DD,
Epstein SE. Malignant hypertrophic cardiomyopathy: identification of a sub-group of families with unusually frequent premature death. Am $f$ Cardiol 1978; 41: 1133-40.

${ }^{39}$ Spray TL, Marron BJ, Morrow AG, Epstein SE, Roberts WC. A discussion on hypertrophic cardiomyopathy. Am Heart f 1978; 95: 511-20.

${ }^{40}$ Noakes TD, Rose AG, Opie LH. Hypertrophic cardiomyopathy associated with sudden death during marathon racing. Br Heart $\mathcal{f} 1979$; 41 : 624-7.

${ }^{41}$ Pomerance A. Infiltrations and storage diseases. In: Pomerance A, Davies MJ, eds. Pathology of the heart. Oxford: Blackwell, 1975.

${ }^{42}$ Davies MJ, Moore BP, Braimbridge MV. The floppy mitral valve-a study of incidence pathology and complications in surgical necropsy and forensic material. Br Heart $\mathcal{f} 1978$; 40: 468-81.

${ }^{43}$ Campbell RWF, Godman MG, Fiddler GI, Marquis RM, Julian DG. Ventricular arrhythmias in syndrome of balloon deformity of mitral valve. Definition of possible high risk group. Br Heart $\mathcal{F} 1976$; 38: 1053-7.

${ }^{44}$ Krikler D, Curry P, Kafetz K. Preexcitation and mitral valve prolapse. $\mathrm{Br}$ Med $\mathcal{F}$ 1976; 1 : 1257.

${ }^{45}$ Josephson ME, Harowitz LN, Kastor JA. Paroxysmal supraventricular tachycardia in patients with mitral valve prolapse. Circulation 1978 ; 57: 111-5.

${ }^{46}$ Leichtman D, Nelson R, Gobel FL, Alexander CS, Cohn JN. Bradycardia with mitral valve prolapse-a potential mechanism of sudden death. Ann Intern Med 1976; 85: 453-7.

${ }^{47}$ Ogden JA. Congenital anomalies of the coronary arteries. Am $\mathcal{f}$ Cardiol 1970; 25: 474-9.

${ }^{48} \mathrm{Heggveit}$ HA. Syphilitic aortitis-a clinicopathological autopsy of 100 cases. Circulation $1964 ; 29$ : 346-55.

${ }^{49}$ Harris LS, Adelson L. Fatal coronary embolism from a myxomatous polyp of the aortic valve. An unusual cause of sudden death. Am $\mathcal{F}$ Clin Pathol 1965; 43: $61-4$.

${ }^{50}$ Guthrie W, Maclean $H$. Dissecting aneurysms of arteries other than the aorta. I Pathol 1972; 108: 219-35.

${ }^{51}$ Shaver PJ, Carrig TF, Baker WP. Postpartum coronary artery dissection. Br Heart $\mathcal{F} 1978$; 40: 83-6.

${ }^{52}$ Thiene $G$, Valente $M$, Rossi L. Involvement of the cardiac conduction system in panarteritis nodosa. $\mathrm{Am}$ Heart $\mathcal{F} 1978$; 95: 716-24.

${ }^{53}$ Kegel SM, Dorsey TJ, Rowen M, Taylor WF. Cardiac death in mucocutaneous lymph node syndrome. Am f Cardiol 1977; 40: 282-6.

${ }^{54}$ James TN, Galakov I. De subitaneis mortibus. XXVI. Fatal electric instability of the heart associated with benign congenital polycystic tumour of the atrioventricular node. Circulation 1977; 56: 667-78.

${ }^{55}$ Bharati S, Bicoff JP, Fridman JL, Lev M, Rosen KM. Sudden death caused by benign tumour of the atrioventricular node. Arch Intern Med 1976; 136: 224-8.

${ }^{56}$ Becker AE, Anderson RH, Durrer D, Wellens HJJ. The anatomic substrates of the Wolff-Parkinson-White syndrome. A clinicopathological correlation in seven patients. Circulation 1978; 57: 870-9.

${ }^{57}$ Johansson BW, Jorming B. Hereditary prolongation of 
the QT interval. Br Heart 7 1972; 34: 744-51.

${ }^{58}$ Moothart RW, Pryor R, Hawley RL, Clifford NJ, Blount SG Jr. The heritable syndrome of prolonged QT interval, syncope, and sudden death. Electron microscopic observation. Chest 1976; 70: 263-6.

${ }^{50} \mathrm{James} \mathrm{TN}$, Froggatt $\mathrm{P}$, Atkinson WJ Jr, et al. De subitaneis mortibus. XXX. Observations on the pathophysiology of the long QT syndromes with special reference to the neuropathology of the heart. Circulation 1978; 57: 1221-31.

${ }^{80}$ Davies MJ, Harris A. Pathological basis of primary heart block. Br Heart f 1969; 31 : 219-26.

${ }^{61} \mathrm{Lev} M$. The pathology of complete atrioventricular block. Progr Cardiovasc Dis 1964; 6: 317-26.

${ }^{62}$ Lenegre J. Etiology and pathology of bilateral bundle branch block in relation to complete heart block. Progr Cardiovasc Dis 1964; 6: 409-44.

${ }^{63}$ MacAnulty JH, Rahimtoola SH, Murphy ES, et al. A prospective study of sudden death in "high risk" bundle branch block. $N$ Engl $f$ Med 1978; 299: 209-15.

${ }^{64}$ Denes P, Dhingra RC, Wu D, Wyndham CR, Amat-yLeon F, Rosen KM. Sudden death in patients with chronic bifascicular block. Arch Intern Med 1977; 137: 1005-10.

${ }^{65}$ Anderson RH, Wenick ACG, Losekoot TG, Becker AE. Congenitally complete heart block. Circulation 1977; 56: 90-101.

${ }^{66}$ Stephan E. Hereditary bundle branch system defect. Survey of a family with four affected generations. $\mathrm{Am}$ Heart $\mathcal{f}$ 1978; 95: 89-95.

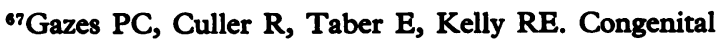
familial cardiac conduction defects. Circulation 1965; 32: 32-5.

${ }^{68}$ Simonsen EE, Madesen EG. Four cases of right sided bundle branch block and one case of atrioventricular block in three generations of a family. Br Heart $\mathcal{f}$ 1970; 32: 501-4.

${ }^{69}$ Gault JH, Cantwell J, Lev M, Braunwald E. Fatal familial cardiac arrythmias. Histologic observations on the cardiac conduction system. Am f Cardiol 1972; 29: 548-553.

${ }^{70}$ Lynch HT, Mohiuddin S, Moran J, et al. Hereditary progressive atrioventricular conduction defect. $\mathrm{Am} \mathcal{f}$ Cardiol 1975; 36: 297-301.

${ }^{71}$ Coumel P, Fidelle J, Lucet V, Attuel P, Bouvrain Y. Catecholamine-induced severe ventricular arrhythmias with Adams-Stokes syndrome in children: report of four cases. Br Heart $\mathcal{F}$ 1978; 40, suppl: 28-37.

${ }^{72}$ James TN, Armstrong RS, Silverman J, Marshall TK. Clinicopathologic correlations. De subitaneis mortibus. VI. Two young soldiers. Circulation 1974; 49: $1239-46$.

${ }^{73}$ James TN, Marilley RJ Jr, Marriott HJ. De subitaneis mortibus. XI. Young girl with palpitations. Circulation 1974; 51 : 743-8.

Requests for reprints to Professor Michael J Davies, Department of Histopathology, St George's Hospital Medical School, Cranmer Terrace, London SW17 ORE. 